http://jmscr.igmpublication.org/home/ ISSN (e)-2347-176x ISSN (p) 2455-0450 crossref DOI: https://dx.doi.org/10.18535/jmscr/v7i7.172

\author{
Journal Of Medical Science And Clinical Research \\ IGM Publication \\ An Official Publication of IGM Publication
}

\title{
Medical Autopsy Need of Time
}

\author{
Authors \\ Harish Bohra ${ }^{1}$, Khethmal $\mathbf{P}^{2^{*}}$, Sukanata Tripathy ${ }^{3}$ \\ ${ }^{1}$ Assistant Professor, Department of Pathology, Government Medical College (RJMES), Pali, Rajasthan \\ ${ }^{2}$ Senior Demonstrator, Department of Pathology, Government Medical College (RJMES), Pali, Rajasthan \\ ${ }^{3}$ Professor, Department of Pathology, Armed Forces Medical College, Pune \\ *Corresponding Author
}

Khethmal P

Senior Demonstrator, Dept of Pathology, Government Medical College (RJMES), Pali, Rajasthan, India

Abstract
With the advent of modern diagnostic technology, use of the autopsy as a means of assessing diagnostic
accuracy has declined precipitously. However, the rate of misdiagnosis found at autopsy has not changed.
The purpose of the present study was to analyze the discrepancies obtained from the comparison between
clinical and autopsy diagnosis in a tertiary care hospital. Medical records, autopsy reports and death
certificates were analyzed for 59 consecutive autopsies performed over a 2 yrs period from Jan 2009 to
Dec 2010, who died in a tertiary care hospital in Delhi. Errors in clinical diagnosis were assigned to one
of four classes as suggested by Goldman. Total Deaths were 1055 and total 59 (5.6\%) autopsies were
performed. The mean age of patients excluding neonates was 36.2 years (range 1 day -59 days) and
average length of stay was 6.2 days (range few hours to 42 days). Major discrepancies involving cause of
death was 17 (28.8\%). Additional findings not detected antemortem were 42 (71.1\%). The class I error
were 10 (23.7\%) of Class II error, 13 (22.1\%) of class II errors, class III 20 (32.3\%) and class IV were 7
(11.9\%). In 9 cases not enough information was found in the medical records to carry out a diagnostic
correlation analysis. Discrepancies between Clinical and Autopsy Diagnosis continues to be high.
Unexpected findings are identified relatively more frequently at autopsy, when the autopsy is proceed by a
short hospital stay.The autopsy remains a vital tool for determining diagnostic accuracy, despite modern
modalities of clinical investigation and diagnosis.

\section{Introduction}

Autos is Greek for oneself and opsis refers to the act of viewing; combined into autopsy, the word refers to the act of seeing for oneself. (1) Campos and Rocha have reviewed autopsies over the past 4000 years and have highlighted their pedagogical value. ${ }^{(2)}$ Autopsy one of the fundamental learning tools since ancient time and it solution to the unresolved clinical diagnosis in current era of molecular biology ${ }^{(3-5)}$. The purpose of an autopsy are to identify the pathological conditions that caused death, to analyze the pathophysiological interaction that influenced the disease and to establish the final clinical-pathological correlation. Despite decreasing trend, it is one the most important learning tool in Medical curriculum all over the world ${ }^{(6,7)}$.

There are various studies in the medical literature which show an important discordance rate between final clinical diagnoses and anatomopathological autopsy diagnoses ${ }^{(8-10)}$. As per Goldman et al, discrepancies between clinical 
diagnoses and autopsy diagnoses were classified as major and minor, according to their level of impact on therapeutic management and patient evolution. Major discrepancies are those in which a different diagnosis would have brought about a change in treatment with a probable impact on clinical evolution and survival. Minor discrepancies are those in which the difference in diagnoses is not directly related to the cause of death and its treatment would not have altered the patient's clinical evolution ${ }^{(11)}$.

Literature review has shown that accuracy of autopsy diagnosis is similar and in some case even higher as compared to available radiological and molecular diagnostic methods over a period of time ${ }^{(12,13)}$. The diagnoses recorded on death certificates are incorrect in up to one third of cases and the final diagnosis reached after the autopsy as the cause of death was clinically unsuspected in up to $50 \%$ of cases $^{(14-15)}$. The purpose of the present study is to analyze the discrepancies obtained from the comparison between clinical and autopsy diagnosis in a tertiary care hospital.

\section{Material and Methods}

Medical records, autopsy reports and death certificates were analyzed for 59 consecutive autopsies performed over a $2 \mathrm{yrs}$ period from Jan 2009 to Dec 2010, who died in a tertiary care hospital in Delhi were reviewed and classified according to main clinical diagnoses, causes of death, age and sex of patients. Final clinical diagnoses were compared with autopsy diagnoses and we determined the type of discrepancy, classifying discrepancies as major, when a different diagnosis would have prompted a change in treatment with a probable impact on clinical evolution and survival and minor, when the difference in diagnoses is not directly related to the cause of death (Table 1). Additionally, we determined the relation existing between the percentage of cases with diagnostic discrepancies and the length of hospitalization (less and more than 24 hours).
In order to ensure diagnostic correlation, the medical records were reviewed for all cases where the clinical information provided in the autopsy protocol was insufficient or when the clinical diagnoses included in the protocol did not match the anatomopathological diagnoses. In 13 cases not enough information was found in the medical records to carry out a diagnostic correlation analysis.

\section{Observations and Results}

Total Deaths were 1055 and total 59 (5.6\%) autopsies were performed. The mean age of patients excluding neonates was 36.2 years (range 1 day - 59 days) and average length of stay was 6.2 days (range few hours to 42 days). Major discrepancies involving cause of death was 19 (32.2\%). Additional findings not detected antemortem were $42(71.1 \%)$. The class I error were $10(23.7 \%)$ of Class II error, $9(15.27 \%)$ of class II errors, class III 19 (32.20\%) and class IV were $8(13.55 \%)$. The errors were classified with respect to age as shown in bar diagram. Remaining 13 cases were excluded from the study as there will be no discrepancies between their antemortem and postmortem diagnosis. The autopsy diagnoses of level I errors are categorized in table 2

Table 1: Classification of Discrepancies

\begin{tabular}{|l|l|l|}
\hline Discrepancies & Class & Description \\
\hline \multirow{4}{*}{ Major } & I & $\begin{array}{l}\text { Missed major diagnosis with } \\
\text { potential adverse impact on } \\
\text { survival and that would have } \\
\text { changed management }\end{array}$ \\
\cline { 2 - 3 } Minor & II & $\begin{array}{l}\text { Missed major diagnosis with } \\
\text { no potential impact on } \\
\text { survival and that would have } \\
\text { not changed therapy }\end{array}$ \\
\hline III & $\begin{array}{l}\text { Missed minor diagnosis } \\
\text { related to terminal disease } \\
\text { but not related to the cause of } \\
\text { death }\end{array}$ \\
\cline { 2 - 3 } & IV & $\begin{array}{l}\text { Other missed minor } \\
\text { diagnosis }\end{array}$ \\
\hline
\end{tabular}


Table 2 Level I post Mortem diagnosis of Level I errors

\begin{tabular}{|l|l|}
\hline Sr. No & Post Mortem Diagnosis \\
\hline 1. & Synovial sarcoma \\
\hline 2. & Subependymomas \\
\hline 3. & Kikuchis disease \\
\hline 4. & $\begin{array}{l}\text { Cerebral Mucormycosis in intracerebral } \\
\text { hemorrhage }\end{array}$ \\
\hline 5. & Acute pancreatitis \\
\hline 6. & Meningoencephalitis with myocarditis \\
\hline 7. & $\begin{array}{l}\text { Left temporal intracerebral } \\
\text { haemorrhage }\end{array}$ \\
\hline 8. & Acute severe bronchial Asthma \\
\hline 9. & Aspiration pneumonia \\
\hline 10. & $\begin{array}{l}\text { Mallory Weiss tear with massive upper } \\
\text { GI bleed }\end{array}$ \\
\hline
\end{tabular}

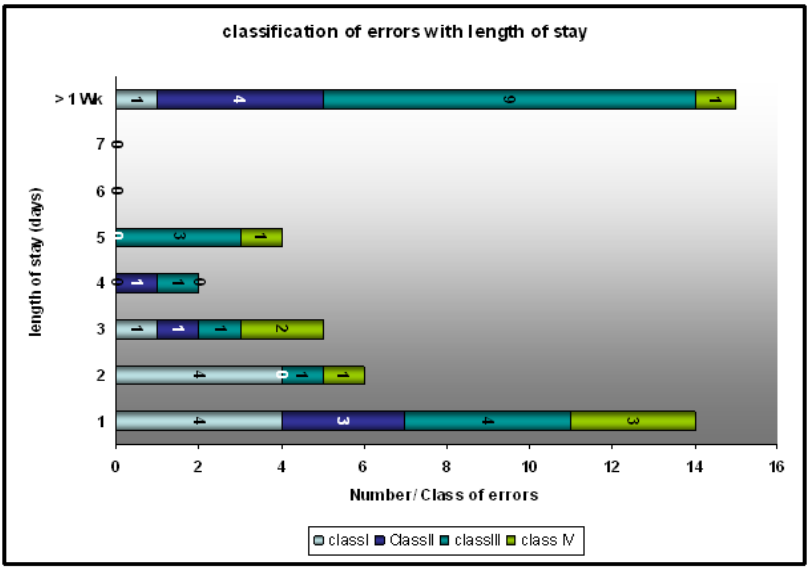

Fig: (1) Bar diagram showing classification of errors with respect to length of stay of patients in hospital

Table 3: Studies on discrepancies reported in the literature

\begin{tabular}{|c|c|c|c|c|c|c|}
\hline Authors & Year & Country & $\begin{array}{c}\text { No of } \\
\text { Autopsies } \\
\text { Reviewed }\end{array}$ & $\begin{array}{c}\text { No of } \\
\text { discrepancies } \\
(\%)\end{array}$ & $\begin{array}{c}\text { Major } \\
\text { discrepancies } \\
(\%)\end{array}$ & $\begin{array}{c}\text { Minor } \\
\text { discrepancies } \\
(\%)\end{array}$ \\
\hline Goldman et al $^{(11)}$ & 1983 & USA & 300 & - & 22 & 60 \\
\hline Battle et $\mathrm{al}^{(21)}$ & 1984 & USA & 2067 & 36.6 & 36.1 & 27.3 \\
\hline Sarode et $\mathrm{al}^{(19)}$ & 1993 & India & 1000 & 48 & 31.7 & 20.3 \\
\hline Pujol et $\mathrm{al}^{(1 \mathrm{II})}$ & 1994 & Spain & 91 & 71.4 & 16.5 & 12.1 \\
\hline Sonderegger et al ${ }^{(13)}$ & 2000 & Switzerland & 300 & 86 & 14 & 0 \\
\hline Twigg et $\mathrm{al}^{(22)}$ & 2001 & $\begin{array}{c}\text { United } \\
\text { Kingdom }\end{array}$ & 97 & 76.3 & 4.1 & 19.6 \\
\hline Silfvast et $\quad \mathrm{al}^{(23)}$ & 2003 & Finland & 346 & 94.5 & 2.3 & 3.2 \\
\hline Richardson et al $^{(10)}$ & 2006 & México & 62 & 75.4 & 8.2 & 6.6 \\
\hline Maria et $\quad \mathrm{al}^{(18)}$ & 2011 & México & 331 & 41.4 & 26 & 15.4 \\
\hline Moorchung et al ${ }^{(20)}$ & 2013 & India & 591 & 23.18 & - & - \\
\hline Present study & 2010 & India & 59 & 77.96 & 32.2 & 45.76 \\
\hline
\end{tabular}

Table 4: Data on Deaths and Autopsy from Annual reports of four major Hospitals of India

\begin{tabular}{|l|c|c|c|c|}
\hline $\begin{array}{l}\text { Name of } \begin{array}{l}\text { Hospital } \\
\text { with year }\end{array} \\
\text { KEM 2017 }\end{array}$ & $\begin{array}{c}\text { Total } \\
\text { deaths }\end{array}$ & $\begin{array}{c}\text { Total } \\
\text { Autopsies }\end{array}$ & $\begin{array}{c}\text { Medico } \\
\text { legal }\end{array}$ & Clinical \\
\hline PGI & 4563 & 480 & 280 & 200 \\
$\begin{array}{l}\text { Chandigarh } \\
\text { (2017) }\end{array}$ & & & & 180 \\
\hline NIMHANS & 830 & 390 & 370 & 20 \\
& $(16-17)$, & $(15-16)$ & $(15-16)$ & $(15-16)$ \\
& 900 & 338 & 322 & 16 \\
$(15-16)$ & $(17-18)$ & $(16-17)$ & $(17-18)$ \\
\hline AIIMS & 3327 & 2659 & 2458 & 14 \\
Delhi & $(17-18)$ & $(17-18)$ & $(14-15)$ & $(14-15)$ \\
& 2723( & 2472 & 2637 & 22 \\
& $14-15)$ & $(14-15)$ & $(17-18)$ & $(17-18)$ \\
& 3035 & 2520 & 2496 & 24 \\
& $(16-17)$ & $(16-17)$ & $(16-17)$ & $(16-17)$ \\
\hline
\end{tabular}

\section{Discussion}

The frequencies of non medico-legal autopsies are declining all over world in recent years. As per one of the studies from USA, the percentage of clinical autopsies decreased from $10.9 \%$ in 1990 to $6.1 \%$ in $1999^{(13)}$. Excluding forensic autopsies, the current percentage of autopsies performed at the Massachusetts General Hospital stands at $13 \%$ (approximately one autopsy per day). As per collective data from annual reports of Post Graduate Institute of Medical Education and Research (Chandigarh), Seth Gordhandas Sunderdas Medical College and King Edward Memorial Hospital (KEM), Mumbai and GMC/JJ, National Institute of Mental Health and NeuroSciences, Bengaluru there were 3105 clinical autopsies performed in 1990 and only 419 in 
$2014^{(16)}$ and (Table 4). As per 2016-17 annual reports of four major tertiary level hospitals of India high percentage of the deaths results from violent events and the autopsies conducted are of the medico-legal type, which is not included in this study. The percentage of clinical autopsies conducted at all these hospitals represents $2.9 \%$ of patients deceased in the same year ${ }^{(17)}$. The percentage of autopsies conducted at the Tertiary level Base Hospital represents $6.8 \%$ of patients deceased in the hospital. This figure, albeit high, reason might be Base hospital was a military hospital where Autopsy was mandatory to claim post mortem economic benefits of patients.

According to some publications, the average autopsy rate at Mexico's national health institutes varies between $25 \%$ to $30 \%$ and it should be between $20-30 \%$ of all deceased for general teaching hospital ${ }^{(10)}$. Relevant clinically unsuspected findings that could have changed patient prognosis if medically controlled or treated are found in $20 \%$ to $40 \%$ of autopsies ${ }^{(14)}$.It is important to point out that the diagnostic discrepancy rate has not decreased significantly over the last 30 years, in spite of the developments in diagnostic methods. In our study the percentage of similar discrepancies is $23.7 \%$ which is consistent with other studies.

In Maria et al out of 331 autopsies, $41.4 \%$ found to have diagnostic discrepancies out of which $26 \%$ were major discrepancies and $15.4 \%$ were minor discrepancies $^{(18)}$. This is in accordance with data reported in the literature. (Table 3). The variable factors responsible this situation are availability of appropriate technology, a rational and judicious use of laboratory and imaging tests to establish the diagnosis and to the practice of good clinical medicine and the length of hospital stay. In our study out of 59 autopsies we found discrepancies in 46 cases $(77.96 \%)$. The major discrepancies (class I and Class II errors) were $32.20 \%$ and minor discrepancies (class III and Class IV errors) were $45.67 \%$. in our hospital deceased were referred from peripheral field hospital where all laboratory and radiological diagnostic modalities, all specialist and super specialist doctors were lacking. So our results were little bit high with respect to the above study despite the responsible factors were same. Tavora analyzed a total of 291 cases and found major discrepancies which were associated to a short length of hospitalization (less than 24 hours) in 50 cases (17.2\% of autopsies). In contrast, in our study the majority of discrepancies corresponded to patients whose length of hospitalization was greater than 24 hours (54.23\%). 3 But approximately $23.72 \%$ discrepancies were associated with less than 24 hours duration. As majority of transferred deceased were terminally ill referred cases from various remote field hospitals.

As per meta-analytic study of approximately 1500 autopsies performed over six decades at Armed Force Medical College Pune; classified final autopsy diagnoses. In 1947, various causes were as Neoplastic-26\%, Infective-34\%, Cardiac-13, Neurological-7\%, Hepatic-9, Congenital-Nil, Renal-2. The similar figures in 2010, were $17.24 \%, 31.03 \%, 6.9 \%, 17.24 \%, 13.79 \%$, Nil, $13.79 \%$ respectively. Newer radiological and molecular diagnostic techniques along with newer drugs and therapeutic modalities were responsible for decline neoplastic, infective, cardiac characteristics of autopsies. While hepatic causes might be increased due to increased alcohol consumption and emerging hepatitis $\mathrm{B}$ and $\mathrm{C}$ viral infections (20). Our study shows $42.37 \%$ (25) infectious, $33.89 \%$ (20) hepatic causes, $3.3 \%$ (2) neoplastic, $5.0 \%$ (3) cardiac, $6.7 \%$ (4) renal (2) $3.3 \%$ nervous, respiratory $3.3 \%$ (2) and $1.6 \%$ (1) congenital. Infectious and hepatic causes are consistent with the literature. Predominantly septicemia followed by multiorgan failure is terminal event so we can-not definitely categorize the causes in our study as discussed above.

The results of this study prove the autopsy will be the definite solution to find exact cause of death in previous era and current modern diagnostic era. The mean percentage of discrepancies between 1980-2000 was 48.8\% (36.6-86\%) and that between 2001 to 2013 is $62.16 \%$ (23.18- 
$94.5 \%)$. Our result is also consistent with that of literature $(77.96 \%)$. Though infectious diseases remains the most frequent unsuspected diagnosis, which also happens in studies reviewed in the literature $^{(3,14,17)}$. This shows apparently easily diagnosable diseases are culprit for death of many hospitalized patients. Early diagnoses and treatment can save the lives. We believe that autopsies should be a mandatory procedure in undergraduate and postgraduate medical education. It is essential to increase the number of autopsies to achieve real monitoring of this practice in order to keep and maintain a reliable medical information database, as well as to provide feedback with this information to the training programs of the different medical specialties.

\section{Conclusion}

Medical autopsy is essential tool for apparently easily diagnosable diseases leading to death of many hospitalized patients. Discrepancies between clinical and autopsy diagnoses related to duration of hospitalized patient and severity of disease. We believe that autopsies should be a mandatory procedure in undergraduate and postgraduate medical education.

\section{References}

1. Pai SA. Autopsy. In: Lock S, Last JM, Dunea G (eds). The Oxford illustrated companion to medicine. Oxford:Oxford University Press; 2001:88-90..

2. Campos FPF, Rocha LOS. The pedagogical value of autopsy. Autops Case Rep 2015;5:1-6.

3. van den Tweel JG, Taylor CR. The rise and fall of the autopsy. Virchows Arch 2013;462:371-80

4. Pujol FR, Bernet VM, Castellsague J, et al. Análisis de concordancia entre diagnósticos clínicos y de autopsia en un hospital general. An Med Interna 1994;5:48-56..
5. Tavora F, Crowder CD, Sun CC, et al. Discrepancies between clinical and Autopsy diagnosis: A comparison of University, Community, and Private Autopsy practices. Am J Clin Pathol 2008;129:102-109.

6. Nemetz PN, Tanglos E, Sands LP, et al. Attitudes Toward the Autopsy - An 8State Survey. Medscape General Medicine 2006;8:80.

7. Arce MF, Fernández FF, Mayorga FM, et al. La autopsia clínica. Revista Electrónica de la Autopsia 2009;7.

8. Pakis I, Polat O, Yayci N, et al. Comparison of the clinical diagnosis and subsequent autopsy indings in medical malpractice. Am J Forensic Med Pathol 2010;31:218-221.

9. Ayoub T, Chow J. The conventional autopsy in modern medicine. J R Soc Med 2008;101:177-181.

10. Richardson LCV, Coronel MDL. Discrepancia entre los diagnósticos clínicos y por autopsia en un hospital pediátrico de tercer nivel. Bol Med Hosp Infant Mex 2006;63:232-240.

11. Goldman L, Sayson R, Robbins S, et al. The value of the autopsy in three medical eras. N Engl J Med 1983;308:1000-1005.

12. Minces P, Schnitzler E. Necropsy: The importance of being aware of discrepancies. Pediatr Crit Care Med 2006;7:487-488.

13. Sonderegger K, Burger S, Muntwyler J, et al. Diagnostic errors in three medical eras: a necropsy study. Lancet 2000;355: 20272031.

14. Mark EJ. The state and use of the autopsy around the world. Histopathology 2002; 41:197-21

15. Roulson J, Benbow EW, Hasleton PS. Discrepancies between clinical and autopsy diagnosis and the value of post mortem histology; a meta-analysis and review. Histopathology 2005;47:551-559. 
16. Editorials 'Living in the clouds of a vain illusion':The decline and fall of clinical autopsies THE NATIONAL MEDICAL JOURNAL OF INDIA VOL. 29, NO. 3, 2016 125-128.

17. The annual reports (2016-17) Post Graduate Institute of Medical Education and Research (Chandigarh), Seth Gordhandas Sunderdas Medical College and King Edward Memorial Hospital (KEM), Mumbai, All India Institute of Medical Sciences New Delhi and National Institute of Mental Health and Neuro Sciences, Bengaluru.

18. María Victoria González-Franco, Marco Antonio Ponce-Camacho, Oralia BarbozaQuintana, Jesús Ancer-Rodríguez, Luis Angel Ceceñas-Falcón. Discrepancies between clinical and autopsy diagnosis: A study of 331 autopsies performed over a 7 years period. Medicina Universitaria 2012;14(54):16-22. 